\title{
ANGUSTIA Y EVASIÓN EN LA NARRATIVA DE RIMA DE VALLBONA
}

\author{
Lee A. Daniel \\ Texas Christian University
}

La decisión de leer Mujeres y agonías en vez de otro libro de Rima de Vallbona para este estudio de su ficción corta fue motivada por los comentarios breves sobre los relatos en la introducción de la colección prologada por Luis Leal. El concluye sus palabras con "encontramos cierta ira reprimida causada por las injusticias, la descriminación social o sexual y la inhabilidad de los pueblos nuestros para resolver sus problemas, que parecen ser crónicos" (9). Es notable que este tema general del libro todavía tenga resonancia en 1995. Y puesto que la ponencia debe tener una duración máxima de 15 minutos, elegí estudiar cuatro cuentos de este libro que representan bien la cuentística de Vallbona-"Parábola del edén imposible", "Beto y Betina", "Bajo pena de muerte" y "El impostor." En cada uno figura específicamente la angustia en sus varias formas, dos de las víctimas que sufren son mujeres y dos son hombres. También, en cada cuento, y se manifiesta en diversas maneras, los protagonistas buscan un escape del infierno en que se encuentran. "Parábola del edén imposible" trata de una mujer que no se siente completa en su existencia cotidiana. Para ella la vida es como un infierno ritual y sus quehaceres diarios son como la condena de Sísifo. Se ve su angustia y su frustración cuando nos informa que "había vivido en plena conformidad enterrada viva por años, siglos, milenios, cumpliendo con el quehacer de Sísifo" (22). Ella entiende que para evadir su condena debe viajar a su paraíso soñado en su "nave-soñada-hacia-el-paraíso" (22). Por fin, logra realizar su meta y en su paraíso se siente completa y por primera vez, mujer. Sin embargo, al pasar un año de felicidad descubrió que todo "fue tomando la forma de lo cotidiano, de lo repetido" (24) y que "se hundió de nuevo en el infierno de la costumbre" (24) y que finalmente "comenzó a mirar con añoranza la orilla que una tarde abandonó llena de esperanzas..." (25). Parece que ahora acepta la importancia de lo que ya sabía pero no apreciaba. Es decir, que como "la sacerdotisa de un rito necesario para que la máquina de la vida de su casa continuara" la vida de esposa y madre es importante, a pesar de lo repetido, porque cada mujer contribuye a la continuación del ser humano.

En "Beto y Betina" los nombres del título sugieren dos personajes distintos, uno hombre y el otro mujer. Sin embargo, Vallbona nos descubre con gran destreza el mundo angustiado en que Alberto Corrales es Beto entre semana en su trabajo en la oficina y se convierte en su hermana gemela Albertina los fines de semana, es decir, Beto es Betina. Aunque el cuento comienza como termina, el lector no puede comprender el significado de lo que lee en el primer párrafo antes de haber leído toda la historia. Por todo el cuento el lector experimenta la lenta 
evolución del cambio sexual en que "la otra ficticia" es hecha carne y hueso al terminar el relato. Beto, después de una ausencia prolongada de su lugar de trabajo, regresa como su hermana gemela a la oficina en un acto simbólico. En las últimas líneas, y con toques maestros de Vallbona, Beto le confiesa a Isabel que es Beto, y agrega "en persona." Con esta palabra femenina se hace la transición en la que Betina recuerda a su colega cuando una vez las dos habían compartido confidencias sobre su íntimo malestar ante la sensación de faltarles algo. Le explica a Isabel que se va al extranjero a realizar su paraíso porque ahora es completa, es total, es Albertina. Parece que con la confesión Betina busca la bendición o el aliento de Isabel, su "hermana" simbólica, con el fin de poder cruzar el puente figurativo para aceptar que se había cambiado física y mentalmente a su nuevo ser para por fin vivir en paz consigo misma y con los otros.

El lector comparte con la señora Jacinta de Benavides la angustia que ésta experimenta mientras ella busca el cadáver de su esposo para enterrarlo en "Bajo pena de muerte." Para mostrar la magnitud de su angustia Vallbona emplea lo que es casi un estribillo con la repetición de las dos preguntas: “¿Dónde lo han matado? ¿Dónde han dejado el cadáver?” El joven Pablo es el narrador y el hijo del difunto juez José Benavides que fue asesinado por razones políticas, y que bajo pena de muerte "no se ha de enterrar [al juez] y pena de muerte al que lo entierre" (69). Se ve todo a través de los ojos de Pablito. Por eso aceptamos su idea de que su madre, que antes de la tragedia era pequeña y débil, al aceptar su responsabilidad, y en virtud de su empresa heróica, crece físicamente. En un lugar Pablito preguntaba, "¿Había crecido durante la noche, pues ahora él tenía que empinarse mucho para mirarla a los ojos?" (66). Sin embargo, más tarde cuando ella falla leemos que "una a una las palabras del sepulturero fueron amenguando la talla de su madre y la volvían a su tamaño de antes" (69). Vallbona toca con sensibilidad el tema del desaparecido, los soldados deshumanizados, y el humano brutalizado que resulta de ello. Realiza esto en parte porque el narrador es joven. Pablito ve la búsqueda del cadáver, y usando las palabras de Leal, como una odisea en su descenso al infierno. El simbolismo es obvio por ocurrir la búsqueda en la noche y con palabras como "oscuridad," "negrura," "oscuro" y "tinieblas." La oscuridad muestra los límites del ser humano, su inabilidad de ver y comprender el presente o ver el futuro. Sin embargo, nos da alguna esperanza cuando la señora de Benavides, a pesar de su angustia, muestra su gran humanidad al no insistir en que el supulturero le entregue el cadáver, pues el acto lo condenaría. Evade su angustia por su dignidad, lo que inspira en Leal lo siguiente: "La figura de doña Jacinta resalta como una de las más logradas y admirables en la narrativa hispanoamericana."

"El impostor" es una joya narrativa, o mejor, toda una mina de alhajas para el lector de mente alerta y aficionado al análisis y a un juego refinado. Se puede resumir la trama del cuento al estilo de un recorte periodístico o un anuncio del noticiero: "Profesor universitario trastornado por demasiado trabajo asesina al decano de la facultad. Los celos parecen ser el motivo del homicidio." La trama básica de "El impostor" es muy sencilla, pero la vida de los dos protagonistas con sus dobles y sus motivos reales y alegados producen tanta tela para la especulación que se puede descubrir algo nuevo con cada lectura. El narrador, un profesor no identificado, mata a su colega Pedro Romero quien ha sido su amigo desde la niñez. Además, el colega es decano de la Facultad de Artes y Ciencias en una universidad en el norte de la República Mexicana donde el narrador dicta cursos de cultura y civilización hispanoamericanas. Ya que el decano es un pariente lejano del conde y el narrador tiene interés en la historia, a los dos les inte- 
resa mucho esta persona histórica, el Conde de Regla. También los dos tienen acceso a objetos del pasado que tienen resonancia en el presente, como por ejemplo el retrato del conde, un mandato escrito por él y algunos documentos olvidados que la bisabuela le mandó al decano.

Empleo el realismo mágico y la ekphrasis para comentar "El impostor." En este cuento se ve la intrusión de sueños en la realidad y la contaminación de la realidad por sueños; el doble (en forma de transmigración del alma); y, en un sentido, la inversión de acontecimientos que son técnicas del realismo mágico. Pero antes de continuar, creo que vale la pena aclarar este término que se usa a menudo pero que cada quien define a su manera hasta casi perder sentido. Para mí, el realismo mágico no es más que lo que implican las dos palabras. La obra magicorealista es principalmente realista. Pero, con la ayuda de la magia otros niveles de realidad son posibles. Sin embargo, hay que poner énfasis en el hecho de que con la excepción de la vía mágica que permite otro nivel de la realidad, todo es realista. Aunque el profesor-narrador viaja mágicamente entre siglos, es aceptable porque lo hace mientras duerme, pero dentro de cada época todo transpira normalmente. El realismo mágico tampoco es fantástico en el sentido de la fantasía que es común en la ciencia ficción. Se ve esta diferencia importante en las hazañas fantásticas de Superman y otros personajes ficticios en la literatura de la ciencia ficción. Superman vuela y es dotado de potencias no humanas que no puede esperar poseer ningún hombre real. Sus actividades fantásticas no son las que esperamos en la vida cotidiana de la realidad. Otra literatura más seria en el campo de la fantasía es la de Jorge Luis Borges. Borges nos recuerda en Nueva antología personal que Samuel Taylor Coleridge capturó la esencia de la literatura fantástica así: "Si un hombre atravesara el Paraíso en un sueño, y le dieran una flor como prueba de que había estado allí, y si al despertarse encontrara esa flor en su mano. . ." (216). En "El milagro secreto" de Borges el tiempo es congelado por un año para que Jaromir Hladík tenga el tiempo que necesita para terminar mentalmente el drama que éste compone. El instante en que él escribe la última oración de la obra, se resume el fluir del tiempo y es fusilado (25). Con la excepción del retrato o la foto, no se puede congelar el tiempo en la realidad que vivimos como se hace en el cuento de Borges, y por eso la acción es increíble o fantástica. Otro ejemplo de la fantasía que no es realismo mágico, a pesar de lo que opinan algunos, es la escena de Cien años de soledad en la que un hilo de sangre sale de una casa, cruza la calle y entra en otro domicilio.

Un hilo de sangre salió por debajo de la puerta, atravesó la sala, salió a la calle, siguió en un curso directo por los andenes disparejos, descendió escalinatas y subió pretiles, pasó de largo por la calle de los Turcos, dobló una esquina a la derecha y otra a la izquierda, volteó en ángulo recto frente a la casa de los Buendía. (182).

Bien interesante todo esto pero, a lo menos en mi realidad, esto no pasa nunca con la sangre. En contraste, en el "El impostor" todo lo que hacen los personajes en las dos épocas es realista. Sin embargo, lo que ocurre no pasaría si no fuera por la magia que permite que el narrador viva en dos siglos simultáneamente. En este cuento el aspecto mágico es el viaje en el tiempo y la transmigración del alma pero lo demás es realista. Por ejemplo, el Conde de Regla, aunque en el cuerpo del decano en la versión del profesor-narrador, sigue el plan original de su vida.

El enfoque central del cuento es el viejo retrato al óleo cubierto de pátina del Conde de Regla. El retrato, que figura más tarde en nuestros comentarios sobre ekphrasis, ha permaneci- 
do en la pared a espaldas del decano desde que éste adquirió esta posición. El narrador es profesor de cultura y civilización hispanoamericanas y es especialista en el conde de Regla y su época. Éste nos relata su erudición en el tema y se jacta de que "no había detalle de su vida ni de su época, ajeno a mí" (32). Hay que saber que el narrador-profesor está obsesionado con el conde desde la niñez. Nos dice que "comenzamos [él y el decano] a interesarnos cuando descubrimos, entre papeles amarillentos, un mandato suyo", es decir, del conde (27-28). El narrador agrega que él fue el que soñó antes que el decano, en la adolescencia, la impostura del Conde de Regla (34). Es notable lo que dice el narrador en su locura a continuación: "Sin embargo él fue quien llegó hasta el extremo mimetismo de parecerse al Conde, de ser él y vivir la vida del Conde en mis sueños, de vivir mi propia y única vida en mis sueños" (34, las cursivas son mías). Es decir, el narrador considera que él debe vivir la vida del Conde pero el decano Pedro Romero le roba esto como le había robado también el decanato que él cree que merece por jerarquía y antigüedad y, el colmo, el robo de su dulce María Antonia. Luego, el narrador-profesor confiesa que había matado al decano Pedro Romero porque lo detestaba y era necesario y nos dice que "Era preciso matarlo o morir yo" (35). Es interesante notar que el decano mismo había dicho antes, en una conversación con el narrador, que daría su vida por ser el conde y vivir lo que él vivió (30). Se supone que el decano no sabía nada de lo que pasó en los sueños del narrador pero definitivamente pierde su vida por ser el conde en la mente del narrador.

Ahora bien, a mi juicio, la ekphrasis es clave para entender "El impostor." Un pintor desconocido pintó el retrato del conde de Regla que sirve de punto de unión entre el siglo XVIII y el siglo XX. El retratista capturó, con el retrato, un objeto del pasado que existe y vive en el presente. El narrador-profesor, también sin nombre y especialista en el conde y su época, es el "pintor verbal" ideal para la reelaboración del retrato y por eso aquí entra el papel de la ekphrasis. La ekphrasis en términos sencillos, y en palabras de James A.W. Heffernan, es la representación verbal de una representación visual (3). El origen de la ekphrasis se encuentra en la descripción del escudo de Aquiles en la Iliada de Homero. Dado lo inabarcable de los límites espacio-temporales del escudo, no se puede representar plásticamente toda la acción de la escena, lo que exige su descripción por vía verbal. Entonces el origen es la imagen pero la imagen no puede existir independiente de su descripción. Esto es precisamente lo que ocurre en "El impostor." La imagen del conde, muerto por doscientos años, cobra vida en la reelaboración por el tratamiento de la ekphrasis. Con los documentos ya mencionados que dan ímpetu a su obsesión con el conde, el narrador puede interpretar el retrato, lo que permite al narrador incorporar en su ekphrasis elementos de carácter subjetivo que transfiere a la representación plástica la intensidad y el dramatismo que se encuentra en el nivel onírico. El retrato así dotado de voz y movimiento por el doble marco onírico-ekphrástico, toma vida en los sueños del narrador-profesor lo que en su turno revitaliza la leyenda del Conde de Regla y hace explícito el paralelismo que existe entre los dos siglos y los dos parientes a pesar del espacio grande que existe entre ellos. De los cuatro personajes - el narrador-profesor y el decano pertenecen al siglo XX y cada quien es el doble del conde y el pintor original del retrato del siglo XVIII. El narrador, quien es implícitamente el nuevo pintor, cambia el retrato y por ekphrasis permite que el decano viva la impostura del conde en sus sueños. Entonces, dentro del contexto de la ekphrasis el narrador viene a ser pintor y lo que escribe se basa principalmente en el retrato del Conde de Regla. 
Para concluir, se ve claramente la angustia que sufre cada protagonista y la manera de escapar de su infierno. Beto, como Betina, intenta una nueva vida en el extranjero; la mujer-sísifo cree que su felicidad está en otro lugar; la señora Jacinta de Benavides intenta la evasión de su vida tímida y dócil para vivir con dignidad como viuda; y el profesor-narrador asesina a su rival para no morir él mismo. Sin embargo, uno no puede sino dudar del futuro de Betina; la mujer-sísifo entiende que su vieja prisión es igual a la nueva; la señora viuda crece, lucha, falla y luego disminuye en tamaño y espíritu; y el narrador-profesor padece su angustia y no puede evadir su destino ni en el sueño ni en la locura. Todos sufren su angustia y al fin de cuentas, no hay escape. Pero llegar a esta conclusión presupone una lectura de estos cuatro cuentos que son el producto de una de las cuentistas más logradas y admirables de la narrativa hispanoamericana.

\section{Bibliografía}

Borges, Jorge Luis. 1965. Nueva antología personal. Buenos Aires: Emece Ediciones. 1969. "El milagro secreto.” En: Coleman (ed.).

Coleman, Alexander (ed.). 1969. Cinco Maestros: Cuentos modernos de Hispanoamérica. New York: Harcourt, Brace \& World, Inc.

Daniel, Lee A. 1982. "Realismo Mágico: True Realism With a Pinch of Magic." South Central Bulletin.

de Vallbona, Rima. 1982. "El impostor.” Mujeres y agonías. Houston: Arte Público Press.

García Márquez, Gabriel. 1983. Cien años de soledad. Madrid: Espasa-Calpe, S.A.

Heffernan, James A.W. 1993. Museum of Words: The Poetics of Ekphrasis from Homer to Asbery. Chicago: The University of Chicago Press. 
